\title{
PROCESSING OF COIR - A BIOLOGICAL APPROACH TO RETTING OF COCONUT HUSKS
}

\author{
By
}

\author{
ANITA DAS RAVINDRANATH ${ }^{1}$
}

\begin{abstract}
'White coir fibre is extracted from coconut husks after 'retting' for a period varying between six to ten months depending upon several environmental factors. With a view to explore the possibility of reducing the prolonged period required for retting and improving the quality of the coir fibre a field study was conducted at Azhikode in the N. Parur regions of Kerala which is a 'poor'* retting area. Selected strains of efficient pectin and phenol degrading bacterial cultures were inoculated into pits containing lots of husks soaked for retting. Samples of husks were analysed at regular intervals for details of degradation of the husk constituents holding the individual fibres together. It was observed that inoculation of the bacterial strains could shorten the period of retting by two and a half months and yield an improved quality of fibre with respect to colour and texture. The detaiis of the experimental field study are presented in this paper.
\end{abstract}

\section{INTRODUCTION}

India ranks first among the coir producing nations in the world, although it ranks third among the coconut growing countries in the world after Philippines and Indonesia. 'Retted' coir fibre or 'white' fibre is versatile hard fibre having an average length of $35 \mathrm{cms}$ and diameter ranging from 0.3 to $1.0 \mathrm{~mm}$ and used in the manufacture of floor coverings (mats, mattings, carpets) and cordage. Coir products have found varied end uses like coir matting being used in sand stowing operations in coal mines $^{2}$ in place of normal barricading materials like bamboo mats since coir mats can be reused. Coir matting has also found its use in roof surface cooling and controlling sea erosion ${ }^{3}$.

The coir fibre is extracted from coconut husks subjected to retting in the natural backwaters either in pits covered by soil and coconut leaves or in large nets (malis). Environmental factors like temperature, water quality, water movement by tidal action control the efficiency of retting and the quality of the retted fibre. As retting progresses the different constituents in the husk holding the individual fibres together viz. polyphenols and pectins are biologically degraded, thereby liberating the individual fibres from their natural setting in the husk.

The lignocellulosic bondage that constitutes the coir fibre is normally resistant to microbial attack and hence the fibre is not disintegrated by the retting process.

The present study was initiated with a view to shorten the prolonged period required for producing quality fibre. It was studied that the presence of polyphenols leached out during the soaking of coconut husks results in inhibiting the proliferation of microorganisms responsible for bringing about the degradation of the binding constituents in the husk. It was therefore envisaged that by inoculation of polyphenol and pectin degrading species of microorganism during retting could help in the faster degradation of the polyphenols and thereby allowing the survival of microorganisms involved in retting and consequently shortening the period of retting to the essential minimum.

\footnotetext{
${ }^{1}$ Central Coir Research Institute, Kalavoor, Alapuzha 688 522, Kerala, India.

* Dull coloured fibre produced after 10 (ten) months retting.
} 


\section{Materials and Methods:}

In the experimental work coconut husks were steeped in lots of 5000 in duplicate. Three aerobic and one anaerobic species of bacterial cultures viz. Pseudomonas aeruginosa, Pseudomonas desmolyticum, Psuedomonas resinovorans and Clostridium felsineurn known for phenol and pectin degradation were grown in nutrient medium and mass multiplied in the same medium. The bacterial cultures were transported to the field site in sterile distilled water and inoculated into the lot of husks after 40 days of steeping. Suitable controls (without inoculation of the cultures) were maintained to examine the effect of bacterial inoculation on the progress of retting. The inoculation was repeated four times at monthly intervals after the first inoculation. Husk samples were collected from the the steeped lots before each inoculation for study of the microbial count and estimation of the pherol and pectin contents. Simultaneously sample husks were drawn from the control (uninoculated) lot of husk. The observations recorded at different stages of retting are furnished in Tables I and II and the difference in the colour of fibres is evident in Plate I.

Results and Discussion: The experimental study was conducted in a comparatively 'poor' retting area where fibre could be extTacted only after retting for a period of nine to ten months.

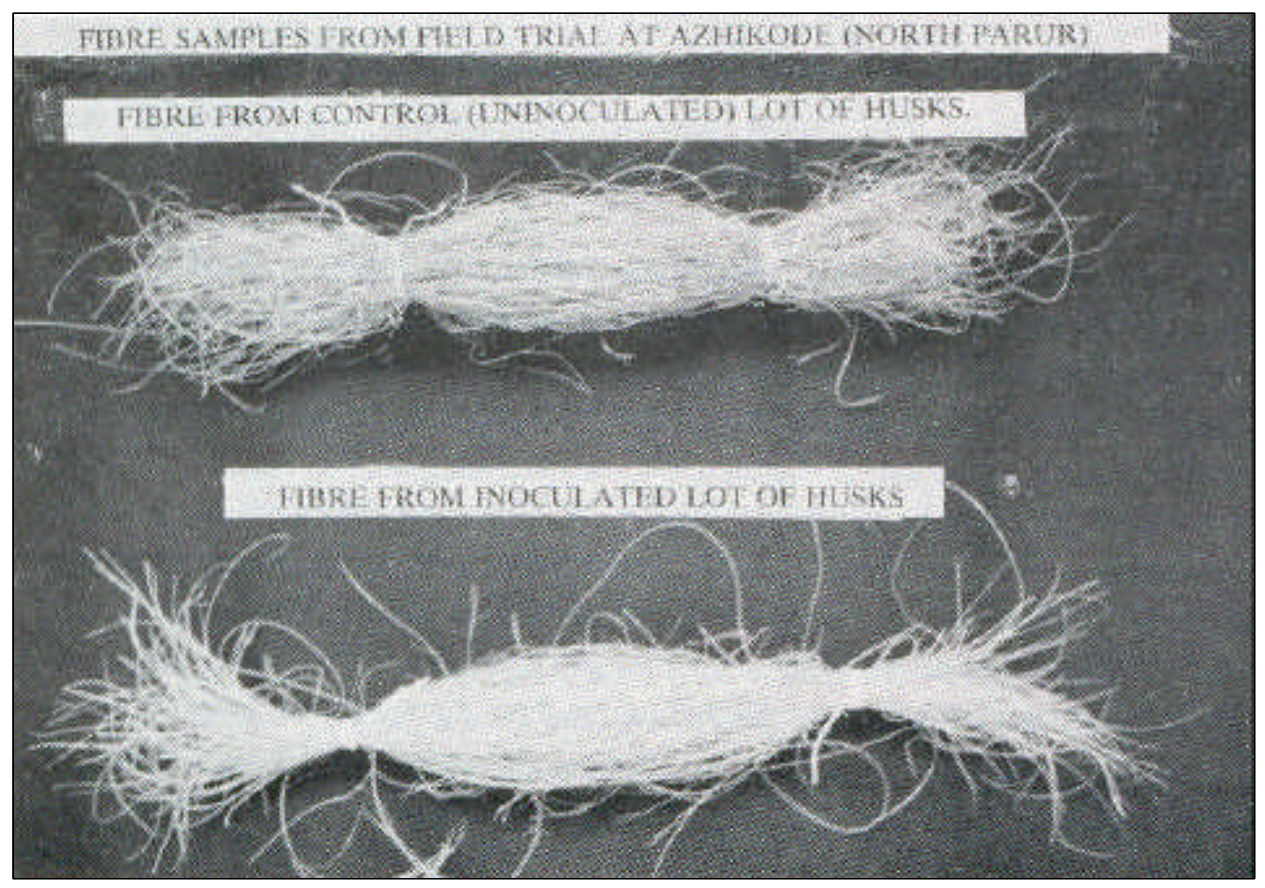

Table - I Microbial population in Coconut Husk Samples at different Stages of retting (Bacterial Count x 103)

\begin{tabular}{|l|c|c|}
\hline \multicolumn{1}{|c|}{ State of retting } & Specimen Inoculated Lot & Colleeted from Control Lot \\
\hline 1. Before Steeping & 82 & 82 \\
2. Before $1^{\text {st }}$ Inoculation & 270 & 230 \\
3. Before $2^{\text {nd }}$ Inoculation & 300 & 250 \\
4. Before $3^{\text {rd }}$ Inoculation & 330 & 270 \\
5. Before $4^{\text {th }}$ Incoulation & 350 & 280 \\
6. Before $5^{\text {th }}$ Inoculation & 320 & 290 \\
\hline
\end{tabular}


TABLE - II Pectin and Phenol Content of Coconut Husk

(g/Kg. of dry husk)

\begin{tabular}{|l|c|c|c|r|}
\hline \multicolumn{1}{|c|}{ State of retting } & \multicolumn{2}{|c|}{ Pectin Content } & \multicolumn{2}{c|}{ Phenol Content } \\
\hline & Inoculated & Control & Phenol Content & Control \\
\hline 1. Before Steeping & 17.0 & 17.0 & 70.0 & 70.0 \\
2. Before $1^{\text {st }}$ Inoculation & 14.6 & 14.8 & 42.0 & 43.0 \\
3. Before $2^{\text {nd }}$ Inoculation & 12.9 & 13.5 & 41.0 & 42.0 \\
4. Before $3^{\text {rd }}$ Inoculation & 11.4 & 13.0 & 33.0 & 36.0 \\
5. Before $4^{\text {th }}$ Incoulation & 8.4 & 11.5 & 22.0 & 28.0 \\
6. Before $5^{\text {th }}$ Inoculation & 6.2 & 9.5 & 10.0 & 24.0 \\
\hline
\end{tabular}

The observations of the analysis of pectin and phenol contents in the sample husks showed that the fall in contents is at an accelerated rate in the samples drawn from the inoculated lot of husks as against the samples drawn from the control lot signifying hastening of retting on inoculation of bacterial cultures into the lot of husks steeped for retting.

The quality of the fibre extracted from the husks samples drawn from the inoculated lot was observed to be brighter in colour and of a supple feel compared to the fibre extracted from husk samples drawn from the control lot. The investigations reveal that inoculation of bacterial cultures into the mass of husks steeped for retting results in hastening the retting process with improvement in the colour of the fibre.

Production of Coir and Coir Products in India

\begin{tabular}{|l|r|r|r|r|r|}
\hline \multicolumn{1}{|c|}{ Item } & \multicolumn{1}{c|}{$1985-86$} & \multicolumn{1}{c|}{$1986-87$} & \multicolumn{1}{c|}{$1987-88$} & \multicolumn{1}{c|}{$1988-89$} & $1989-90$ \\
\hline Coir Fibre White & 122,880 & 135,000 & 130,600 & 117,000 & 125,900 \\
Brown & 43,700 & 50,000 & 53,900 & 71,100 & 75,800 \\
Coir Yarn & 101.890 & 106,980 & 107,610 & 107,000 & 115,400 \\
Coir Products & 19,920 & 20,500 & 19,320 & 21,470 & 23,490 \\
Coir Rope & 37,650 & 38,000 & 34,650 & 37,000 & 39,600 \\
Curled Coir & 5,200 & 5,500 & 7,300 & 8,100 & 9,000 \\
Rubberised Coir & 4,500 & 5,000 & 6,000 & 13,500 & 15,000 \\
\hline
\end{tabular}

Source: Annual Report Coir Board 1989-90. 


\section{REFERENCES}

BHAT, J.V. and A.N.D. NAMBUTHIRI 1971. The Uniquity of Coir Retting, J. Scient. Ind. Res. Vol. $3017-28$

ANONYMOUS 1981 - Evaluation of Coir Matting as a Barricading Material for Stowing in Mines. Coir Vol. 25 No. 4; 8 - 11

ANONYMOUS 1981 - Use of Coir Materials for Sea Erosion Control. Coir Vol. 26, No. 1; 13 - 15

JAYASANKAR, N.P. 1985 - An Appraisal on the Biological Extraction of Coir - Proceedings of the Workshop on Coir Research; $2^{\text {nd }}$ September 1985

NAGARAJAN, R. DAS ANITA SREEKUMAR 1985 - Effect of Prior Crushing on Retting of Coconut Husks - Proceedings of the Workshop on Coir Research, $2^{\text {nd }}$ September 1985.

\section{ANITA BAS RAVINDRANATH}

Ms. Anita Das Ravindranath at present is a scientific assistant (microbiology) at the Central Coir Research Institute in Kerala. She has eight years research experience in the field of coconut husk retting. Her work centred on the process improvement in extraction of white fibre and the identification of chemical and biochemical factors involved in the retting process. She has co-authored two research papers on field studies in retting of coconut husk titled, "Effect of prior crushing on the retting of coconut husk" and "Studies on seeding of ret microflora on coconut husks. 